\title{
Managing climate-change-induced overheating in non-residential buildings
}

\author{
André Badura ${ }^{2, *}$, Birgit Mueller ${ }^{2}$, and Ivo Martinac ${ }^{1}$ \\ ${ }^{1}$ KTH Royal Institute of Technology, ABE Division of Sustainable Buildings, 11428 Stockholm, Sweden \\ ${ }^{2}$ HTW Berlin, University of Applied Sciences Building Energy Technology, 12459 Berlin, Germany
}

\begin{abstract}
Large and rapid climatic changes can be uncomfortable and sometimes hazardous to humans. Buildings protect people from external climatic conditions, and also mitigate the impacts of external climate extremes through their design and construction, as well as with the help of dedicated building service and other technical systems. Active space conditioning accounts for more than 30 per cent of the overall final energy use in Germany. In the life cycle of a building, the construction phase (planning and construction) is the phase with the shortest duration. However, the quality applied during this phase has a significant impact on the resources required, as well as the overall building performance during the much longer operational phase. Once built, buildings are often unable to adapt to boundary conditions that were not considered in the original building design. Consequently, changing outdoor climate conditions can result in an uncomfortable indoor climate over the lifetime of a building. The aim of this study was to determine the effectiveness of flexible solutions for reducing winter heating loads and to reducing/avoiding summer cooling loads in nonresidential buildings in Germany. Various external shading scenarios for non-residential buildings were analysed using the IDA ICE indoor climate and energy simulation tool. Key simulation parameters included the orientation and location of the building, as well as the envelope structure. We investigated the impacts of solar shading on heat storage in the building mass and indoor climate and how different types of envelopes affect overall energy use. The result shows that the use of an adaptive building envelope allows a higher reduction of the total energy demand by $7 \%$ to $15 \%$ compared to an increase in insulation thickness only.
\end{abstract}

\section{Introduction}

In Germany, active space conditioning (space heating and cooling, domestic hot water and ventilation) accounts for one-third of total final energy use. The building envelope as a connecting link between the inside and outside has an important impact on the overall energy requirement. Measures such as decreasing the heat transfer coefficient or shading windows are used to reduce energy consumption. These measures avoid the influences of the outside climate, but not the influences through internal sources.

In the present study, the application of an adaptive building envelope for an office building in Berlin (Germany), located in a moderate climate zone, was analysed through a simulation of a one-zone model.

This study is the second in a series of studies on adaptive building envelopes. In the first part of the study, the application of the adapted building envelope for a residential building use was investigated and led to the reduction of the energy demand for heating and cooling of 20 per cent compared to an application of a fixed building envelope.

The aim is to provide a comfortable thermal indoor temperature through applying the adaptive building envelope. The adaption was achieved by using two different building envelope types depending on previously defined parameters. The IDA-ICE tool was used to simulate and evaluate different variations.

\subsection{Design of building envelopes}

In this study, for an office building in Germany, three different building envelope types (BETs) were examined. The BETs represent designs according to different guidelines. Building envelope type A (BET-A) was used before 1980, BET-B was designed according to the German Heat Insulation Ordinance 82/84 and BET-C was designed according the German Energy Saving Ordinance. The used materials and its properties are listed in Tables 1 to 3. Type A is a wall with $0.01 \mathrm{~m}$ of plaster in the inside and the outside layer, the layer in the middle is a $0.25 \mathrm{~m}$ thick brick layer. Type B has one more insulation layer, $0.05 \mathrm{~m}$ thick, between the brick and the outside plaster layer. Type $\mathrm{C}$ is the wall type that has two additional layers on the outside, made of $0.09 \mathrm{~m}$ of insulation and a final plaster layer. The U-value of Type B was built according to [2], the U-value of Type $\mathrm{C}$ according to [3]. The BETs were initially analysed separately, but in the further course of this

* Corresponding author: abadura@kth.se 
study, they were used combined to evaluate the influence of the adaptation of a façade that can react to the indoor and outdoor environments to provide users with constant comfort without wasting a lot of energy.

Table 1. Overview of design and properties envelope type A

\begin{tabular}{ccccc}
\hline Type A & {$[\mathrm{m}]$} & {$[\mathrm{W} / \mathrm{mK}]$} & {$\left[\mathrm{kg} / \mathrm{m}^{3}\right]$} & {$[\mathrm{Wh} / \mathrm{kgK}]$} \\
\hline Plaster & 0.010 & 0.380 & 1000 & 1000 \\
Brick & 0.250 & 0.560 & 1200 & 1000 \\
Plaster & 0.010 & 0.380 & 1000 & 1000 \\
& & & $\mathbf{1 . 5 2 0}$ & $\mathbf{W} / \mathbf{m}^{2} \mathbf{K}$ \\
\hline
\end{tabular}

Table 2. Overview of design and properties envelope type B

\begin{tabular}{ccccc}
\hline Type B & {$[\mathrm{m}]$} & {$[\mathrm{W} / \mathrm{mK}]$} & {$\left[\mathrm{kg} / \mathrm{m}^{3}\right]$} & {$[\mathrm{Wh} / \mathrm{kgK}]$} \\
\hline Plaster & 0.010 & 0.380 & 1000 & 1000 \\
Brick & 0.250 & 0.560 & 1200 & 1000 \\
Insulation & 0.050 & 0.045 & 200 & 1450 \\
Plaster & 0.010 & 0.380 & 1000 & 1000 \\
& & & $\mathbf{0 . 5 6 7}$ & $\mathbf{W} / \mathbf{m}^{2} \mathbf{K}$ \\
\hline
\end{tabular}

Table 3. Overview of design and properties envelope type C

\begin{tabular}{ccccc}
\hline Type C & {$[\mathrm{m}]$} & {$[\mathrm{W} / \mathrm{mK}]$} & {$\left[\mathrm{kg} / \mathrm{m}^{3}\right]$} & {$[\mathrm{Wh} / \mathrm{kgK}]$} \\
\hline Plaster & 0.010 & 0.380 & 1000 & 1000 \\
Brick & 0.250 & 0.560 & 1200 & 1000 \\
Insulation & 0.050 & 0.045 & 200 & 1450 \\
Plaster & 0.010 & 0.380 & 1000 & 1000 \\
Insulation & 0.090 & 0.045 & 200 & 1450 \\
Plaster & 0.010 & 1.000 & 1800 & 1000 \\
& & & $\mathbf{0 . 2 6 5}$ & $\mathbf{W} / \mathbf{m}^{2} \mathbf{K}$ \\
\hline
\end{tabular}

\subsection{Zone Model}

A zone model was created with the IDA-ICE tool. The zone model has one external wall type (see Figure 1). which was simulated with different types of layers (see Caption 1.1; BET-A, BET-B and BET-C) and different types of orientation (north, east, south and west).

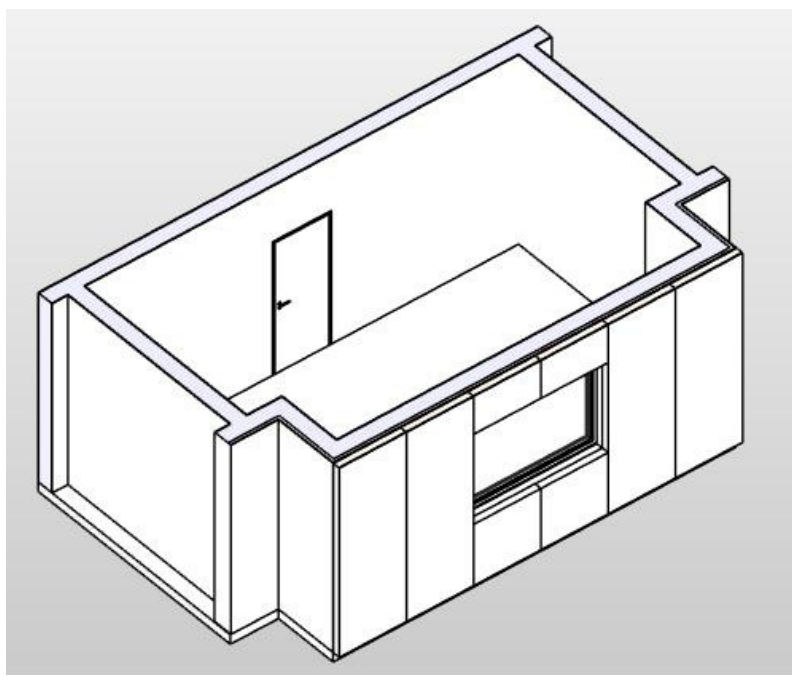

Figure 1. Used zone model in IDA-ICE; the zone model is in the state BET-C.
The zone is made of one single room $2.90 \mathrm{~m}$ high, $5.50 \mathrm{~m}$ wide and $4.00 \mathrm{~m}$ deep. The window is placed at a standard height of $0.80 \mathrm{~m}$, and it has $2.20 \mathrm{~m}$ per $1.50 \mathrm{~m}$, so that the window area in relation to the room is $21 \mathrm{Per}$ cent. It is placed centred in the façade that is being assessed (north, east, south or west).

All zone models were used with the same window type according to current German guidelines; the Uvalue of the window is $1.24 \mathrm{~W} / \mathrm{m}^{2} \mathrm{~K}$ and the $\mathrm{g}$-value is 0.59 .

This allows the application of the adaption of the building envelope types in the further steps.

The heat transfer of the zone model was designed only between the inside and the outside through the building envelope (external wall). Additional used parameters and settings are shown in the following list:

- The set point for the heating device is $20^{\circ} \mathrm{C}$ and for the cooling device $26{ }^{\circ} \mathrm{C}$, controlled to the operating temperature.

- Heating and cooling were provided by one element placed under the window.

- All windows had an external shading device, controlled depending on the outside solar radiation of $100 \mathrm{~W} / \mathrm{m}^{2}$. A light control according to the light intensity into the zone was not used.

- The air tightness of the building was set to $3.0 \mathrm{~h}^{-1}$ (minimum requirement of German Energy Saving Ordinance); a ventilation system was not used. The schedule for window opening three times a day was used.

- People have been assigned a schedule for their presence in an office building. Two people are included in the zone.

- For the lighting there was allocated a schedule for an office building with $40 \mathrm{~W}$, controlled after the presence of persons and brightness in the zone.

- Two devices were used in the zone: a computer $(150 \mathrm{~W})$ and a monitor $(50 \mathrm{~W})$ for each person, scheduled according to the presence of the person.

- The area of the zones is $22 \mathrm{~m}^{2}$.

\subsection{Adaption of the building envelopes}

The adaption of the building envelope is achieved by using the insulation panels before the external wall, which means the BET-C with the highest level of insulation (see Figure 1) or the insulation panels stored sideward to the zone (BET-A or BET-B state, see Figure 2). Through this switched insulation, the building envelope type can be chosen depending on demand.

The adaption is achieved with the use of the simulation results from Step 1. In these simulations, parameters such as indoor temperature, outdoor temperature and the energy demand for heating and cooling were examined. Through the change between the BET-A and BET-C or BET-B and BET-C, the BETadapted state was created.

The adaption is calculated depending on a limit temperature (see Table 5). The time of the measurement is defined individually for each orientation. 


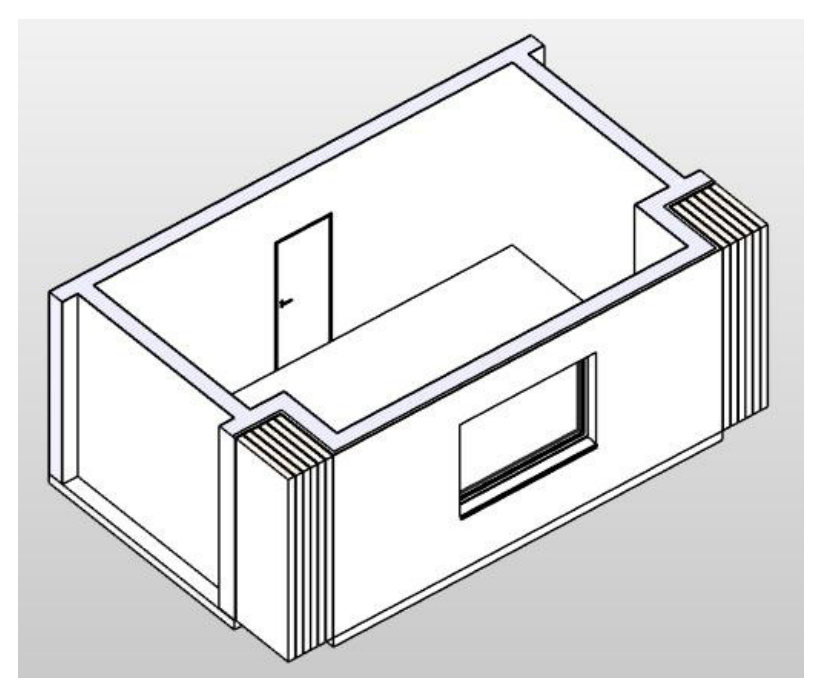

Figure 2. Zone model, state of BET-B, the insulation is stored sideward of the zone.

When the outside temperature reaches the limit temperature, the BETs change accordingly. Considering the results of the previous study [1], one daily change is enough to optimise the energy demand. This rate of adjustment of the BET is also used in the present study.

\section{Simulation methodology}

\subsection{Model evaluation}

The model in IDA-ICE was created, simulated and verified stepwise with five versions. The results of the version were used for the application of the adapted building envelope. The different versions are shown in Table 4. Version 1 is important for determining the course of the indoor temperature. For that, the window shading is non-existent, as are the heating, cooling and the internal loads. This analysis shows the annual indoor temperatures to identify how often during the year it is necessary to heat or cool the zone. Version 2 adds only the window shading to assess the effect it has on the indoor temperature without any other change. The third version adds a heating system to determine the heating energy demand of the zone. Version 4 also adds the internal loads, still without cooling. The last version calculates the zone with all the considered participants. By splitting the analysis in these five versions, it is possible to understand the influence of each option.

Table 4. Overview of the versions (1)

\begin{tabular}{ll}
\hline Version 1 & Determining the course of indoor temperature \\
& Window shading - no \\
& Heating - no \\
& Cooling - no \\
& Internal loads - no \\
\hline Version 2 & Effect of window shading on the indoor temp. \\
& Window shading - yes \\
& Heating - no \\
& Cooling - no \\
& Internal loads - no \\
\hline
\end{tabular}

\begin{tabular}{|c|c|}
\hline Version 3 & $\begin{array}{l}\text { Determining of the heating energy demand } \\
\text { Window shading - yes } \\
\text { Heating - yes } \\
\text { Cooling - no } \\
\text { Internal loads - no }\end{array}$ \\
\hline Version 4 & $\begin{array}{l}\text { Determining of the heating energy demand } \\
\text { with internal loads } \\
\text { Window shading - yes } \\
\text { Heating - yes } \\
\text { Cooling - no } \\
\text { Internal loads - yes }\end{array}$ \\
\hline Version 5 & $\begin{array}{l}\text { Determining of the heating and cooling energy } \\
\text { demand, with internal loads } \\
\text { Window shading - yes } \\
\text { Heating - yes } \\
\text { Cooling - yes } \\
\text { Internal loads - yes }\end{array}$ \\
\hline
\end{tabular}

\subsection{Adaptive building envelope}

The adaption of the building envelope was done depending on a limit temperature, a time of measurement of the temperature (time when the limit temperature is compared with the outside temperature) and the rate of adjustment. The iterations used are shown in Table 5.

Table 5. Overview of the used iterations of the application of the adapted BET

\begin{tabular}{ll}
\hline $\begin{array}{l}\text { Iteration 1 } \\
\text { (for all zones) }\end{array}$ & $\begin{array}{l}\text { Limit temperature: } 10{ }^{\circ} \mathrm{C} . \\
\text { Time of measurement: } 4 \text { p.m. } \\
\text { Rate of adjustment of the BET once a day. }\end{array}$ \\
\hline Iteration 2 & $\begin{array}{l}\text { Limit temperature: } 10^{\circ} \mathrm{C} . \\
\text { Time of measurement: } 4 \text { a.m. and } 4 \text { p.m. } \\
\\
\text { Rate of adjustment of the BET: Twice a day }\end{array}$ \\
\hline Iteration 3 & Limit temperature: $10^{\circ} \mathrm{C}$. \\
& $\begin{array}{l}\text { Time of measurement: } 4 \text { a.m., } 10 \text { a.m., } 4 \\
\text { p.m. and } 10 \text { p.m. }\end{array}$ \\
& $\begin{array}{l}\text { Rate of adjustment of the BET: Four times a } \\
\text { day }\end{array}$ \\
\hline Iteration 4 & $\begin{array}{l}\text { Limit temperature: Individual } \\
\text { (for all zones) }\end{array}$ \\
& $\begin{array}{l}\text { Time of measurement: Individual } \\
\text { Rate of adjustment of the BET: Once a day. }\end{array}$ \\
\hline
\end{tabular}

\section{Results}

\subsection{Adaption of the building envelopes}

For the heating and cooling, an electric devise is used to provide the heating and cooling energy in the simulation. Both are considered using a coefficient of performance (COP), for heating with 1.0 and for cooling with 3.0. The use of a COP for heating and cooling considers the energy required by the heating and cooling devices.

For the south and north zones, the specific energy demand for heating and cooling in Iteration 1 for all three BETs are shown in Figure 3. As expected, the specific heat energy demand (dark grey bars) decreases with increased thickness of insulation (BET-A no insulation to BET-C highest insulation). 


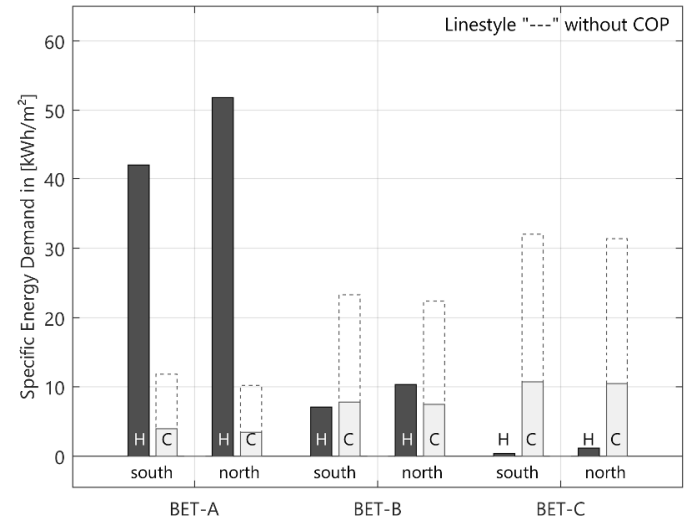

Figure 3. Specific energy demand (heating and cooling) of zone north and south for the BET-A, BET-B and BET-C, dashed line bars energy demand for cooling without COP respectively

The specific cooling energy demand (light grey bars) increases with the increased insulation. For the used climate zone, a further increase of the insulation level will not lead to a further reduction of the energy demand for heating and cooling. This characteristic can also be observed for the zones east and west (see table 6).

Table 6. Overview of the results of specific zone energy demand for BET-A, BET-B and BET-C (with COP) in $\mathrm{kWh} / \mathrm{m}^{2}$

\begin{tabular}{lcccc}
\hline Zone & South & West & North & East \\
\hline Heating & & & & \\
BET-A & 41.9 & 47.3 & 51.8 & 48.0 \\
BET-B & 7.0 & 9.2 & 10.3 & 9.3 \\
BET-C & 0.3 & 0.8 & 1.1 & 0.7 \\
\hline Cooling & & & & \\
BET-A & 4.0 & 4.2 & 3.4 & 4.1 \\
BET-B & 7.8 & 7.7 & 7.5 & 7.8 \\
BET-C & 10.7 & 10.5 & 10.5 & 11.1 \\
\hline
\end{tabular}

The adaption of the BET should achieve a higher reduction of the specific energy demand for heating and cooling, then the use of a higher insulation level only. The results of the adaption between the BET-A and BET-C for the zone south are shown in Figure 4. The total specific energy demand (TSED) for heating and cooling for the zone with the BET-A amounts to $45.9 \mathrm{kWh} / \mathrm{m}^{2}$. The insulation of BET-C reduces the TSED by 76 per cent, to $11.0 \mathrm{kWh} / \mathrm{m}^{2}$. The main part of the specific energy demand in BET-C results from the cooling load.

The use of the BET-adapted leads to a higher reduction of the total specific energy demand by 9 per cent compared to the BET-C use only. The TSED of the zone accounts for $7 \mathrm{kWh} / \mathrm{m}^{2}$. The main part of the specific energy demand is requested to provide the cooling load in the BET-C zone, as well as in the BETadapted zone. The small difference of the TSED between the use of BET-C or BET-adapted results from the high heat losses through BET-A.

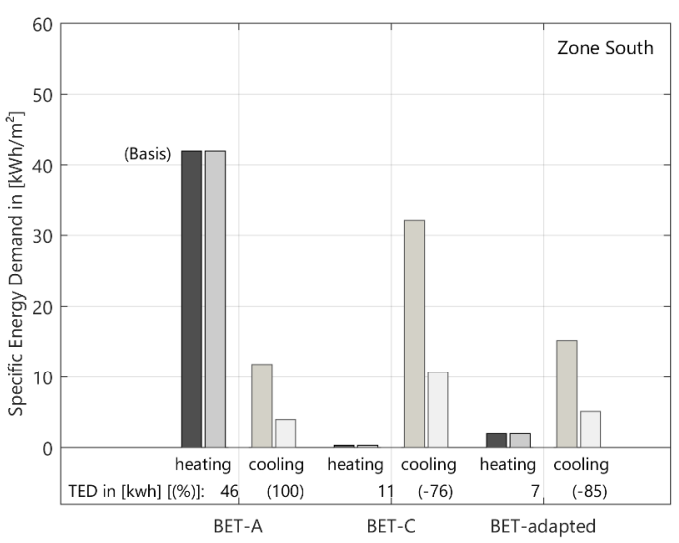

Figure 4. Specific energy demand (heating and cooling) of the zone south for the BET-A, BET-C and the result of adaption as BET-adapted, the right bars with COP - respectively

Figure 5 shows the results of the adaption between the BET-A and BET-C for the north zone. Similarly, to the south zone provides the use of the adaption building envelope for the north zone a higher reduction of the TSED, compared to use of BET-C. The reduction of the total specific energy demand accounts for 86 per cent compared to the use of BET-A and is therefore higher than the use of the BET-C.

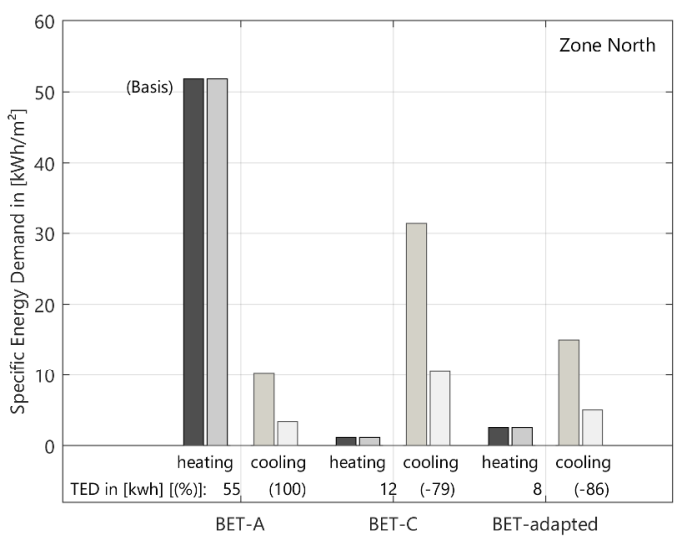

Figure 5. Specific energy demand (heating and cooling) of the zone north for the BET-A, BET-C and the result of adaption as BET-adapted, the right bars with COP - respectively

Further results of the west and east zones are listed in Table 7, in comparison to the south and north zones. The results are similar to each other.

Table 7. Overview of the results of specific zone energy demand for BET-A, BET-C and BET-adapted (with COP) in $\mathrm{kWh} / \mathrm{m}^{2}$; percentage change in brackets.

\begin{tabular}{lcccc}
\hline Zone & South & West & North & East \\
\hline BET-A & 45.9 & 51.5 & 55.2 & 52.1 \\
& $(100)$ & $(100)$ & $(100)$ & $(100)$ \\
BET-C & 11.0 & 11.3 & 11.6 & 11.8 \\
& $(-76)$ & $(-78)$ & $(-79)$ & $(-77)$ \\
BET-adapted & 7.0 & 8.0 & 7.5 & 7.9 \\
& $(-85)$ & $(-85)$ & $(-86)$ & $(-85)$ \\
\hline
\end{tabular}


Figures 6 and 7 show the results for the adaption between the BET-B and BET-C. The use of the adaption of the BETs leads to a higher reduction of the total specific energy demand up to 15 per cent for the south zone. Also, for the east zone, a reduction of TSED of up to 15 per cent was feasible. This is possible because the energy requirement mainly consists of the cooling load.

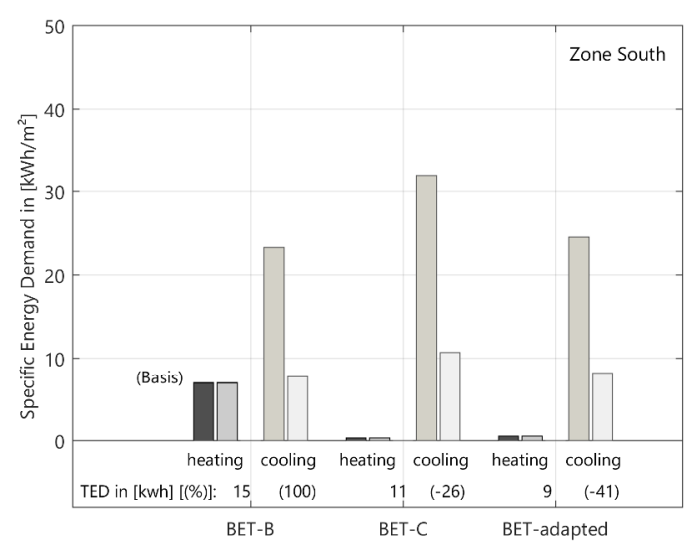

Figure 6. Specific energy demand (heating and cooling) of the south zone for the BET-B, BET-C and the result of adaption as $\mathrm{BET}$-adapted, the right bars with COP, respectively

For the north and west zones, the reduction of the TSED compared to the use of BET-C accounts for 13 per cent, due the fact that the cooling demand of the north zone is lower than in the other zones.

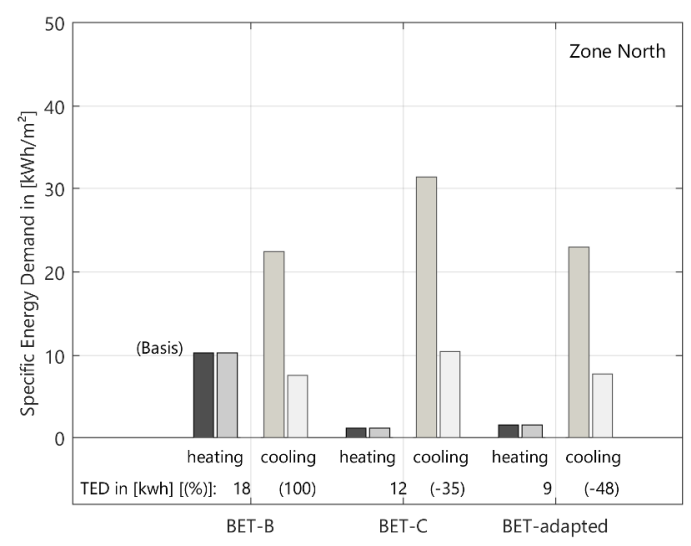

Figure 7. Specific energy demand (heating and cooling) of the zone north for the BET-B, BET-C and the result of adaption as BET-adapted, the right bars with $\mathrm{COP}$ - respectively

To prevent the heating energy demand from increasing significantly, the BET-C was used more often. The results of the zones west and east are listed in table 8 in comparison to zone south and north.

The frequency of use of each building envelope type are shown in figure 8 . The use of the BET-A and BET-B (dark grey bars), the less insulated building envelope type, are used more often than the BET-C. This underlines the statement that a further fixed increase of the insulation thickness will not provide a positive effect on the total specific energy demand of the building.
Table 8. Overview of the results of specific zone energy demand for BET-B, BET-C and BET-adapted (with COP) in $\mathrm{kWh} / \mathrm{m}^{2}$, percentage change in brackets

\begin{tabular}{lcccc}
\hline Zone & South & West & North & East \\
\hline BET-B & 14.8 & 17.0 & 17.8 & 17.1 \\
& $(100)$ & $(100)$ & $(100)$ & $(100)$ \\
BET-C & 11.0 & 11.3 & 11.6 & 11.8 \\
& $(-26)$ & $(-33)$ & $(-35)$ & $(-31)$ \\
BET-adapted & 8.7 & 9.1 & 9.2 & 9.2 \\
& $(-41)$ & $(-46)$ & $(-48)$ & $(-46)$ \\
\hline
\end{tabular}

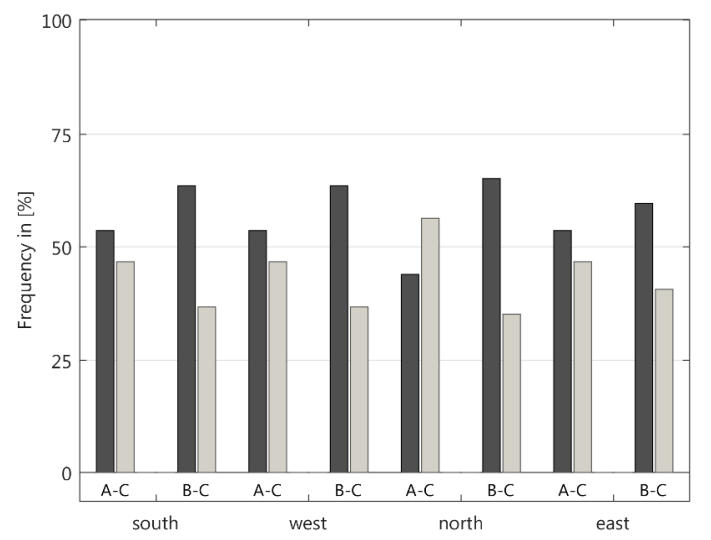

Figure 8. Frequency of the use of BET-A, BET-B, BET-C listed according the orientation of the zones.

\section{Conclusion}

This study used an application of an adaptive building envelope to achieve a decreased specific energy demand for heating and cooling (without domestic hot water) in an office building in Berlin (Germany) located in a moderate climate zone. The moderate climate zone is characterized by an outdoor air temperature range in which buildings need to be heated and cooled.

The results of the simulation showed that a higher insulation of a building reduces the specific energy demand for heating but increases the specific energy demand for cooling if an acceptable thermal indoor climate is provided. This result accompanies the fact that, in well-insulated buildings, the heat transfer through the building envelope is significantly reduced. A discharge of the building envelope heat load at night is almost impossible. This leads to higher indoor temperatures. Due to the higher temperatures in buildings, a thermal discomfort arises and, especially in cities, can only be prevented by the use of cooling devices. This need for cooling devices in summer is arising in new buildings in Berlin (Germany) and did not required them before. Due to more stringent legislation, such as in the directive on summer thermal insulation [6], it is also apparent that the problem of summer overheating of buildings exists.

The results show that the use of an adaptive building envelope allows a higher reduction of the total energy demand compared to an increase in insulation thickness 
only. Depending on the heat transfer coefficient of the building envelope of an existing building, a higher reduction of 7-15 per cent can be achieved (see Tables 7 and 8), similar results were obtained in [4]. A more detailed definition of the heat generation unit (such as the use of a heat pump) would increase the COP for heating. This would to a much higher percentage reduction of the specific energy demand by using the adaptive building envelope, as shown in the present study.

Furthermore, the application of the adaptive building envelope has shown that, depending on the orientation (south, west, north or east), both types of BET have been used for different periods of time. The building envelopes oriented to the south, east and west were used up to 50 per cent of the year with the smaller insulation thickness. Only the north-oriented zone has used the BET with a high insulation thickness for more than 50 per cent of the year (combination of BET-A and BET-C). This reinforced the suspicion that motivated this study in the first place: only applying more insulation to the buildings is not the most efficient way to reduce energy demand. It is necessary to do more and equip the buildings with smart and flexible envelope so that they are able to react properly to external influences.

Furthermore, the present study did not examine the use of the natural ventilation or the use of a ventilation system. Ventilation systems can be used to reduce cooling loads in rooms. However, if the outside temperature is higher than the inside temperature, the use of ventilation units leads to an additional energy demand. A future investigation will perform a combined application of a ventilation system and an adaptive building envelope.

In total, the additional insulation from BET-B to BET-C leads to a reduction of the specific energy demand for heating. It also leads to a rise in the specific energy demand for cooling. All zones show a benefit from the use of the adaptive building envelope.

\section{Outlook}

In this study, an adaptive building envelope was applied to reduce the specific energy demand for heating and cooling by a one-zone-model with different orientations. The adaption was carried out by combination of simulation results calculated by IDA-ICE. So far, it has not been possible to implement the adaption during an annual dynamic simulation. This means that it is probably possible to achieve even higher savings.

A study for the adaption of the building envelope during the simulation was done by [5], but the necessary module is not available. Furthermore, it is not known if the heat storage of the wall layers is taken into account when an adaption of the building envelope was applied. A future study will apply a module for IDA-ICE, to use an adaptive building envelope during an annual simulation.

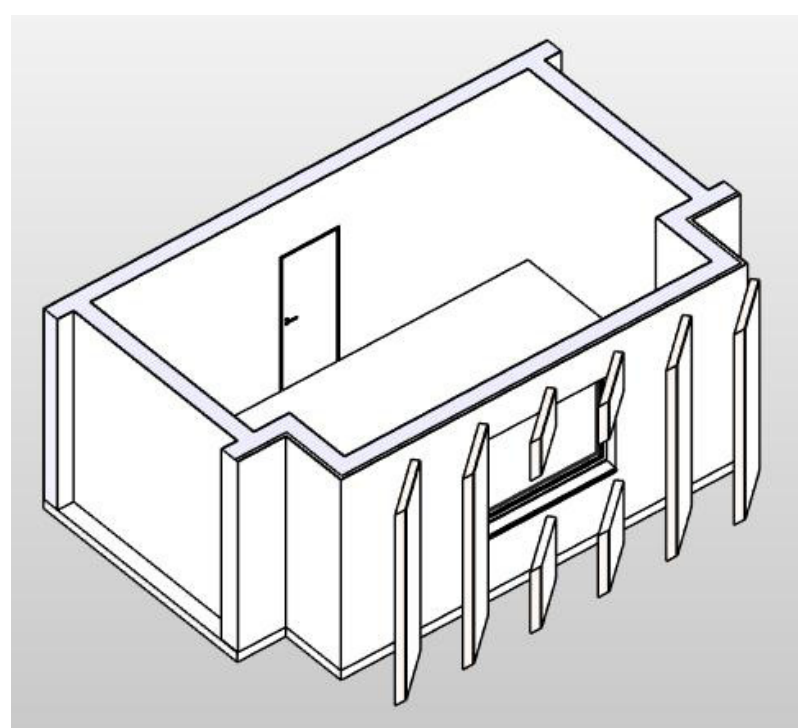

Figure 9. Zone model, the insulation is used as a shading object; the external wall state is BET-A or BET-B

Another future study will examine the effect of shading of the building envelope, as shown in Figure 9. The adaptive building envelope provides the possibility of shading if required. If the building has enveloped the state, as shown in Figure 9, no solar radiation can heat up the surface. Initial studies have shown that the surface temperature of the building envelope is up to $25^{\circ} \mathrm{C}$ higher than the outside temperature. This leads to a heat flow into the building and thus to an increase in the cooling load.

\section{References}

1. A. Badura, B. Müller, I. Martinac, managing overheating in buildings induced by climate-change (to be published)

2. Wärmeschutzverordnung, Verordnung über einen energiesparenden Wärmeschutz bei Gebäuden (1982)

3. M. Tuschinski, Energieeinsparverordnung (EnEV) und Erneuerbare-Energien-Wärmegesetz (EEWärmeG) parallel anwenden (2016)

4. Q. Jin, F. Favoino, M. Overend, Design and control optimisation of adaptive insulation systems for office buildings. Part 2: A parametric study for a temperature climate 127 634-349 (2017)

5. D. Bionda, U. P. Menti, H. Manz, Kann eine Gebäudehülle mit steuerbarem U-Wert zur Reduktion des Kühlenergiebedarfs beitragen Fifth German-Austria IBISA Conference 55 (2014)

6. Thermal protection and energy economy in buildings - Part 2: Minimum requirements to thermal insulation (2013) 